Referencia para citar este artículo: Fernandes, M. L. B. (2018). Os conceitos de Vivência e Reelaboração Criadora para as crianças de uma comunidade quilombola. Revista Latinoamericana de Ciencias Sociales, Niñez y Juventud, 16(1), 213-226. doi:10.11600/1692715x.16112

\title{
Os conceitos de vivência e reelaboração criadora para as crianças de uma comunidade quilombola*
}

\author{
Maria Lidia BUENo Fernandes ${ }^{* *}$ \\ Professora Universidade de Brasília, Brasil.
}

\begin{abstract}
Artículo recibido en mayo 4 de 2017; artículo aceptado en julio 10 de 2017 (Eds.)
\end{abstract}
- Resumo (analítico): Este artigo apresenta reflexões sobre a infância na comunidade Vão de Almas, pertencente ao Território Quilombola Kalunga no município de Cavalcante/GO/Brasil, que assume papel relevante pela sua inserção nas atividades cotidianas, ligadas à economia de subsistência. Em termos teóricos este artigo trabalha na perspectiva da Teoria Histórico Cultural e estabelece uma aproximação tanto com o conceito de Vivência (Perejivanie) quanto o de Reelaboração Criadora (Tvortcheskaia Pererabotka) na perspectiva da unidade pessoa-meio em Vigotski. Trata-se de uma pesquisa qualitativa com a criança e não sobre a criança e tem como objetivo identificar os saberes construídos por elas em sua interação com o meio. Como resultado parcial percebeu-se a forte vinculação entre território e cultura na configuração das identidades dessas.

Palavras-chave: infância, cultura, saber, território (Thesaurus de Ciências Sociais da Unesco).

\section{The concept of Experience and creative reworking for children in a Quilombola community}

- Abstract (analytical): This article presents reflections on childhood in the community of Vão de Almas, Quilombo Kalunga territory, Municipality of Cavalcante, state of Goiás, Brazil. It describes the local children and their daily participation in work-related activities in this selfsustainable economy. This article is based on cultural historical activity theory and describes the concept of Experience (perejivanie in the Quilombola language), as well as the concept of Creative Reworking (tvortcheskaia pererabotka), which is based on the person-environment unit theory developed by Vygotsky. This is a qualitative study conducted with children but not about children, and aims to identify the knowledge gained by children in this specific community through their interaction with the environment. As a partial result, a strong link between territory and culture is fundamental in configuring the children's identities.

Key words: Childhood, culture, knowledge, territory (Unesco Social Sciences Thesaurus).

Este artigo relato de caso corresponde a um estudo de caso na área de Ciências Sociais; sub-área: psicologia e pedagogia a partir de uma metodologia qualitativa. Faz parte da pesquisa Geografia e infância: cultura e território em diálogo com a Teoria histórico cultural vinculada ao Grupo de Pesquisa e Estudos em Geografia da Infância da Universidade Federal Fluminense e Universidade Federal de Juiz de Fora. Financiado parcialmente pelo centro da UnB Cerrado. O recorte da amostra foi entre setembro, 2015 e agosto, 2016. A estrutura utilizada contem quatro partes importantes: introdução, metodologia, resultados e conclusões. Apresenta resultados de um estudo com o fim de conhecer experiências técnicas e metodológicas consideradas específicas. Inclui uma revisão sistemática comentada da literatura dos casos análogos.

** Pós-doutorado na Universidade Federal Fluminense Doutora em Geografia pela Universidade de São Paulo. Especialização em Etnologia e Psicologia Social pela Ludwig-Maximilian-Universität de Munique, Alemanha. Bacharel e Licenciada em Geografia pela Universidade de São Paulo, Brasil. Professora da Faculdade de Educação da Universidade de Brasília. Orcid: 0000-0003-4878-3115. Índice H5: 2. Correio eletrônico: lidia_f@uol.com.br 


\section{Los conceptos de vivencia y reelaboración creadora para los niños y niñas de una comunidad quilombola}

- Resumen (analítico): este artículo presenta las reflexiones sobre la niñez en la comunidad Vão de Almas, perteneciente al territorio Quilombola Kalunga en el municipio de Cavalcante/GO/ Brasil; los niños en dicha comunidad asumen un papel importante en su inserción a las actividades diarias relacionadas con la economía de subsistencia. Este artículo se sustenta en la Teoría HistóricoCultural y establece una estrecha relación tanto con el concepto de Vivencia (Perejivanie) como con el concepto de Reelaboración Creativa (Tvortcheskaia Pererabotka) desde la perspectiva de unidad persona-medio planteada por Vigotski. Se trata de una investigación cualitativa con niños y no de una investigación en el niño; el objetivo es identificar los saberes construidos por los niños y niñas en la interacción con el medio. Como resultado parcial se identifica un fuerte vínculo entre territorio y cultura para la configuración de las identidades de dichos niños y niñas.

Palabras clave: niñez, cultura, saberes, territorio (Tesauro de Ciencias Sociales de la Unesco).

-1. Introdução. -2. Tempo e espaço na região Centro-Oeste. -3. Metodologia. -4. Os Conceitos de Vivência, Reelaboração Criadora e Protagonismo no contexto estudado. -5. Considerações Finais. -Referências.

\section{Introdução}

O presente trabalho apresenta algumas reflexões sobre a infância na comunidade do Vão de Almas, pertencente ao Território Remanescente Quilombola Kalunga, reconhecido pelo Governo do Estado de Goiás em 1991, como Sítio Histórico, situado no município de Cavalcante/GO/Brasil. O território dos Kalunga é, na verdade, um complexo de comunidades, entrelaçadas por afinidades afetivas, relações de parentesco, especificidades culturais e trajetórias históricas em comum. No contexto brasileiro, esta população afrodescendente traz características muito singulares, geradas a partir de uma longa história de isolamento.

A infância nesse grupo assume papel relevante pela sua inserção nas atividades cotidianas, ligadas à economia de subsistência: alimentação dos animais, coleta de frutos ou hortaliças, auxílio na secagem de peixes e carnes, entre outros. As crianças participam ativamente da organização das festas e assumem protagonismo em seus deslocamentos diários, inclusive com relação à ida e volta da escola. Em termos teóricos este artigo trabalha na perspectiva da Teoria Histórico Cultural e estabelece uma aproximação tanto com o conceito de vivência (perejivanie) quanto o de reelaboação criadora (tvortcheskaia pererabotka) na perspectiva da unidade pessoameio em (Vigotski, 2009, 2010), que implica, no âmbito desta pesquisa, na unidade fundada entre a criança e o meio e seu potencial criativo/ criador para (re)interpretar a cultura, a partir de uma atividade organizadora interna no seu enraizamento no mundo, nessa perspectiva a criança reconhece-se capaz, inclusive, de renovar a própria cultura. Assim, entendemos que a configuração da infância, passa-se em um espaço e em um tempo, que marcam profundamente a identidade dessa criança.

A pesquisa em tela é de cunho qualitativo e foi dividida nas seguintes etapas: levantamento bibliográfico, visitas à comunidade e às escolas, entrevistas abertas com a população local, observações diretas em campo, registro fotográfico e convívio com um casal e seus filhos.

O objetivo geral deste trabalho foi registrar e apresentar elementos desse contexto cultural específico e teve como objetivo específico analisar as atividades desenvolvidas pelas crianças e identificar os saberes construídos por elas em sua interação com o meio ambiente e, por fim, refletir sobre como essas crianças, vêm contribuindo para a valorização e manutenção desse modo de vida. Acreditamos que a originalidade deste trabalho está em dar ouvidos 
às vozes infantis, duplamente invisibilizadas, ora por pertencerem a um grupo tratado como resquício de um passado atrasado, ora por fazerem parte de um universo, que, no mundo ocidental, pouco destaque recebe na academia.

$\mathrm{O}$ artigo subdivide-se em introdução, contextualização da comunidade do Vão de Almas do ponto de vista histórico, territorial, político, econômico e social; metodologia; os conceitos de Vivência, Reelaboração criadora e protagonismo no contexto estudado, e, as considerações finais.

\section{Tempo-espaço na região Centro Oeste: contextualizar é preciso}

Apresentamos aqui uma tímida contextualização sobre o estado de Goiás, visando pincelar alguns aspectos das relações políticas, econômicas e culturais, não temos a pretensão de elaborar uma historiografia no sentido stricto, já que, para (Certeau, 1982), a operação historiográfica é a relação necessária entre um lugar, procedimentos de análise e a elaboração de uma narrativa; para o autor, os procedimentos de análise envolvendo a historiografia implicam em selecionar, lembrar e esquecer as sobras do passado a partir de nosso objeto de estudo e de nosso lugar de fala.

Compreendemos que o que fizemos foi a construção de uma narrativa, já que selecionamos as fontes, que dialogam com nossa visão de mundo, iluminamos os fatos e acontecimentos, que, do nosso ponto de vista, e, em diálogo com (Certeau, 1982; Vázquez, 2001) não se encontram em um determinado lugar historiográfico aguardando seu uso por parte dos historiadores e de outros estudiosos; ao contrário, são os pesquisadores que convertem as fontes, os fatos e acontecimentos, por meio de seu discurso em história.

$\mathrm{Na}$ busca do estabelecimento de diálogo com esse universo infantil é necessário que se traga a concepção de espaço que orienta este trabalho, acreditamos que a infância se materializa em um espaço, em um lugar. Nesse sentido, trazemos a abordagem de (Massey, 2015), para quem o espaço é um "encontro de histórias". A autora ainda nos alerta para o risco da assunção da lógica da inevitabilidade de uma forma específica de globalização,

[...] que chega a todos os lugares e hierarquiza esses lugares e considera as diferenças como algo que indique atraso, que deverá ser superado, caso essas áreas remotas, sigam o caminho que o ocidente aponta, e consequentemente trilhou (Massey, 2015, p. 24),

Massey (2015) salienta o fato de que há um cenário, ligado à imagem da globalização que se quer perpetuar em que ocorre a transformação da conceituação de espaço e tempo, ou seja, "transforma a geografia em história e o espaço em tempo”. Assim, para a autora, não se pode negar, ou negligenciar o fato de que esses espaços tem sua própria trajetória, suas próprias histórias específicas, sua multiplicidade de trilhas percorridas e, por isso, traçam seus caminhos para o futuro marcado pela sociedade que lhes confere especificidade. Portanto, para a autora, quando se adota uma única narrativa, ancorada na ideologia que se difunde sobre a globalização, trabalha-se com o olhar para esses espaços, com a ideia de atraso e essa perspectiva de análise, "reduz coexistências simultâneas a um lugar na fila da história” (Massey, 2015).

Dessa forma, nós nos propomos a olhar para aquela realidade, não como resquício, como resto ou resíduo de um tempo que se cristaliza em um determinado espaço, mas como uma intricada rede em suas dimensões políticas, econômicas, sociais e culturais. Sem com isso tecer qualquer processo de hierarquização, ou mesmo de interpretação dos possíveis caminhos a serem tomados pelos agentes sociais que constroem aquele espaço.

Um rápido olhar para a história da ocupação do território brasileiro revela que Região Centro-Oeste do Brasil insere-se tardiamente no processo de expansão da fronteira agrícola no país. A lógica de um país voltado para o litoral e que se ancorava na produção agrícola para exportação, tendo se caracterizado pela exploração da madeira, cana-de-açúcar, cacau, café, entre outros, contribuiu para que o desenho do país e sua perspectiva de olhar se recusassem 
a ver o sertão, a não ser de forma pejorativa, sertão como sinônimo de “desertão”, de vazio, de lugar desprovido de cultura, atrasado, entre outros. Assim, esse termo tem sido muito empregado ao longo de nossa história, para Almeida (1996) o conceito de sertão nessa perspectiva significava o incerto, o atrasado, o desconhecido, o longínquo, o selvagem. A base física que abriga esse entrelaçamento da história e da geografia é marcada pelos "vãos, serras e morros, depressões e vales estreitos, rios encaixados, uma vegetação de cerrado, cerradão e campos cerrados” (Almeida, 2010, p. 37).

A descoberta de ouro no interior do Brasil em meados do século XVIII faz com que o interesse de diferentes grupos econômicos seja reendereçado, mas, ainda assim, a província de Goiás fica alijada de um projeto de ocupação e mais consistente. São poucas as fazendas ou referências sobre "Goyas”, a não ser pelas investidas dos bandeirantes e pela consolidação de alguns projetos, como é o caso da Fazenda Babilônia em Pirenópolis, ou mesmo de cidades como Planaltina e Formosa e Luziânia, que conheceram certo esplendor, mas têm seu passado invisibilizado a partir da construção de Brasília.

Como descreve (Bertrand, 2011), relatos do século XIX indicam que a população dessa região organizava sua vida em torno de um sistema misto de agricultura e pecuária (bovina e cavalar), da exploração aurífera, entre outras atividades. Descrições de 1886 apontam que "bananas, amendoim, gergelim, agutiguepe, beterraba, cana-de-açúcar, cará, inhame, taiova, mangarito, gengibre, cúrcuma, topinambos, mandioca, batata doce, batata americana, ervadoce, pimenta, ervas medicinais e aromáticas, hortaliças, ervilha, lentilha, feijão, fava, arroz, trigo" brotavam nas roças e quintais na região (Bertrand, 2011).

A produção aurífera na região estimulou a agricultura no século XVIII, entretanto, o século XIX será marcado pela agricultura de subsistência, em um modelo de produção moderado. Entretanto, o Planalto Central foi uma das regiões atingidas pelo grande impulso da chamada modernização do interior do país, a partir do final dos anos 1930, sob o comando do Estado Novo do presidente Getúlio Vargas. A chamada Marcha para o Oeste intensificou a produção agrícola monocultora: tal modelo se baseou no aprofundamento das relações capitalistas de produção, reordenando o espaço a partir das necessidades econômicas -de maneira a considerar "vazios" os espaços que tinham como base o valor de uso da terra-. Portanto, "na construção do novo, a violência e o conflito emergiam como elementos constituintes do processo" (Bandeira, Dantas, \& Mendes, 1990, p. 33).

A partir dessa lógica de ocupação a região se consolida é amplamente afetada pela construção de Brasília, capital federal do país, a partir dos anos de 1950, a partir disso, a região foi incorporada ao sistema produtivo hegemônico, ou seja, monocultura voltada para exportação, em especial da soja, de maneira pujante, mas sem a retaguarda de um estado de direito consolidado, ou mesmo de direitos republicanos ligados à igualdade e democracia, que contemplasse a gama de atores em suas múltiplas especificidades. Nesse sentido, cumpre-nos referendar Bertrand quando se refere à região afirmando ser "uma verdadeira Babilônia de gentes e conflitos potenciais vindos desde as mais remotas origens do homem nas Américas, a contrapor-se a um tipo de história do Distrito Federal que só parece iniciar-se com Brasília” (Bertrand, 2011, p. 71).

Com o regime militar a partir da década de 1960, iniciou-se uma política que, como nos anos 1930/40, privilegiou o desenvolvimento do interior. O modelo agroexportador de hoje tem suas bases no Projeto Polocentro no início da década de 1970, durante o governo de Garrastazu Médici, cujo ministro da Fazenda, Antônio Delfim Neto, foi o principal artífice do chamado milagre econômico brasileiro. A ideia de ocupação implantada pelos militares levou à criação de empresas de colonização altamente rentáveis, assim como intensificou o êxodo rural, a expropriação de terras, os conflitos rurais e a concentração de riquezas. 
Nesse cenário, há o predomínio de um discurso hegemônico que tem inviabilizado a história dos outros grupos, outros modelos de ocupação, outras formas de relação com a natureza, de outras narrativas dos que têm vivido nessas terras no interior do Brasil. Há que se pensar que a região abriga, até hoje, grupos indígenas e quilombolas, fazendas centenárias, uma rede de estradas conectadas às estradas reais ou caminho de tropeiros, enfim, toda uma lógica de ocupação, de relação com a terra, de relação com o outro, com o mítico e religioso, que tem sido ignorada.

\subsection{Os Kalungas neste contexto}

No que diz respeito a este estudo, gostaríamos de trabalhar a partir da fundação oficial do Arraial de Cavalcante, em 1740, com a descoberta de mina de ouro na localidade. Cavalcante está no seio das discussões com seus múltiplos escândalos, ainda ancorado em um sistema de casa grande, que de alguma forma se perpetua. A história da cidade está vinculada à descoberta do ouro no século XVII, entretanto, é a partir do século XIX, com a decadência da exploração aurífera na região e a retomada das atividades agrícolas com a incorporação da atividade pecuária, que se fala em quilombos na região.

O fator desencadeador da presença de quilombos na região ainda é controverso; alguns autores, como (Karasch, 1996; Palacin, 1972), apontam para o isolamento do município, com sua paisagem marcada por chapadas, serras, serrotes, morros, colinas e vales de difícil acesso, como um fator determinante para que se tornasse uma rota de fuga de escravos da Bahia, Maranhão e Pernambuco, que ali encontram o acobertamento para levar a vida em liberdade. Outros falam do declínio do ouro como fator de abandono dos escravos à própria sorte, de forma a liberar os senhores do intenso custo de alimentação dos mesmos, que era bastante oneroso na época. Dessa forma, esses, em busca de proteção e visando assegurar sua liberdade, embrenharam-se nos rincões e interior recôndito da região (Avelar \& Paula, 2009).
O século XX é marcado pela luta pela subsistência por parte desses grupos, que viviam em intenso isolamento. A partir da década de 1970 ocorre um acirramento do processo de grilagem em suas terras, que persiste até a década de 1990. E nem mesmo a legislação de 1985, que assegura a posse coletiva ao grupo, ou a Lei $\mathrm{n}^{\mathrm{O}} 11.409$, sancionada pelo Governo de Estado de Goiás em 21 de janeiro de 1991 que reconhece as terras quilombolas como "patrimônio cultural e sítio de valor histórico”, conseguem conter esse processo de expropriação das terras (Baiocchi, 1990).

Importante debate que marca a segunda metade do século XX e adentra o século XXI alerta para a difusão da ideia de modernidade em contraponto à ideia de comunidade, nesta perspectiva, como abordam Lifschtz y Silva (2007, p. 2) a “vida comunitária geralmente representou a tradição a ser superada. O arcaico devia declinar para que o moderno pudesse emergir". Entretanto, ancorada nas reflexões de (Massey, 2015, p. 26) trabalhamos na perspectiva de "não imobilizar as trajetórias de outros enquanto prosseguimos com as nossas, o desafio real da contemporaneidade dos outros pode ser desviado ao relegarmos a um passado retrógrado, antiquado, arcaico". Portanto, tentaremos apresentar aqui o processo de reinvenção/recriação desse grupo, e capacidade de resistência pela forte vinculação entre território e identidade/cultura.

Na perspectiva de ancoragem no tempo e espaço, cabe-nos ressaltar que abordamos neste artigo a realidade das crianças da Comunidade Vão de Almas, pertencente ao quilombo dos Kalunga situada no município de Cavalcante/ GO, distante cerca de $80 \mathrm{~km}$ da sede municipal. A comunidade situa-se na Chapada dos Veadeiros, um dos derradeiros redutos de Cerrado preservado perante o avanço do modelo de monocultura exportadora que predomina no coração do Brasil.

Os Kalungas tem como especificidade a manutenção de um modo de vida rural, a estrutura das comunidades em casas de 
adobe $^{1}$, distantes umas das outras, assegurando o aprofundamento das relações em núcleos familiares reduzidos. Essa comunidade possui uma profunda compreensão e relação com o bioma Cerrado. Por outro lado, abraçam as tradições festivas, ligadas aos santos católicos e, no caso dessa comunidade, à Nossa Senhora da Abadia, ao Divino Espírito Santo e à Nossa Senhora das Neves. Apesar das singularidades de seu modo de vida, dos elementos culturais que os referenciam, da prática de uma agricultura agrícola de subsistência e das fortes tradições religiosas que os tornaram reconhecidos, ainda assim, a comunidade é marcada pela invisibilidade perante o poder público em todas as instâncias e também por grande fragilidade em termos econômicos e sociais.

O quilombo dos Kalungas é, na verdade, um complexo de comunidades, entrelaçadas por afinidades afetivas, relações de parentesco, especificidades culturais e trajetórias históricas em comum.

Assim, devagarinho o povo Kalunga foi se estendendo pelas serras em volta do rio Paranã, por suas encostas e seus vales, que os moradores chamam de vãos, como viviam em propriedades mais ou menos isoladas, as famílias se distribuíam com largueza por aquelas terras (Secretaria de Educação Fundamental, 2001, p. 27).

No contexto brasileiro, esta população afrodescendente traz características muito singulares, geradas a partir de uma longa história de isolamento. Apesar de suas singularidades, a comunidade é marcada pela invisibilidade e por grande fragilidade em termos sociais e em termos da presença do Estado e de políticas voltadas para sua realidade. Cabe aqui destacar a enorme precariedade das estradas, que faz com que a distância de $80 \mathrm{~km}$ seja transposta em aproximadamente $31 / 2$ horas, em média. $\mathrm{O}$ transporte utilizado é no estilo pau-de-arara, ou seja, caminhões, adaptados precariamente para conduzir passageiros com cobertura de lona na carroceria, e algumas tábuas que fazem as vezes de bancos. Fora isso há o transporte da

1 Blocos de barro cru que secam ao sol, muito utilizados na região para a construção das casas. prefeitura uma vez por mês. Cumpre ressaltar que as comunidades não contam, de um modo geral, com atendimento médico-hospitalar, atendimento odontológico, saneamento básico, água encanada, eletricidade, coleta de lixo, entre outros.

\subsection{A infância na comunidade de Vão de Almas}

A infância nesse cenário é marcada por uma ambiguidade interessante. De um modo geral, as crianças vivem no seu núcleo familiar, transitam livremente pelo entorno da casa nos cinco primeiros anos de vida, acompanham os pais nas tarefas diárias e vão adquirindo autonomia a partir do momento que começam a ir para a escola, com seis ou sete anos. Pelas novas necessidades adquiridas, uma vez por mês, acompanham seus pais à cidade e ali tem contato entre si e com mais adultos pela configuração da Vila Morro Encantando, um loteamento feito para que os Kalungas pudessem construir suas casas também na cidade ${ }^{2}$, com casas muito próximas umas das outras, algumas feitas com adobe, que é a maneira tradicional da região, mas a maioria de tijolo baiano e com telhado de zinco. A proximidade das casas, o acesso à eletricidade, água encanada, a banheiros com coleta de esgoto, já alteram bastante a rotina das crianças na cidade, muitas permanecem com parentes ou pessoas da classe média da cidade, para continuar os estudos a partir dos 13 anos, em troca, prestam serviços, como cuidar das crianças, ajudar nos serviços da casa, entre outros.

$\mathrm{Na}$ comunidade propriamente dita essas crianças transitam entre o universo da casa e o universo escolar. Envolvem-se em deslocamentos diários de alguns quilômetros, muitas fazem o trajeto a pé, acompanhadas de outros colegas, até o local em que o transporte escolar as recolhe, normalmente do outro

2 Este tema é bastante controvertido, a política pública em Cavalcante merecería um capítulo à parte, não é o objetivo deste capítulo, então, apenas citarei esta situação, para contextualizar a realidade das crianças. 
lado do rio, para os moradores da área mais isolada, entretanto, não há transporte escolar, as distâncias são percorridas, em torno de 6 km cada trajeto a pé ou de bicicleta.

Considerando que o clima da regiãoéo clima tropical, alternadamente úmido e seco, segundo a classificação de Strahler y Strahler (2005), temos na região duas estações bem definidas, a da seca e a das chuvas. Durante a estação seca, as estradas ficam muito empoeiradas, mas os rios ficam baixos e podem ser facilmente transpostos a pé. Em contrapartida, quando chove os rios transbordam, várias casas ficam isoladas, muitas crianças arriscam atravessar o rio a nado, o que é muito perigoso, segundo relatos dos pais, em algumas curvas do rio há canoas, para essa transposição, mas também é um processo arriscado.

A comunidade luta pela construção de pontes, o que daria segurança às crianças e tranquilidade aos pais. Por outro lado, nas localidades menos adensadas, em que não passam os transportes escolares, como é o caso do Córrego da Serra, o isolamento das casas é mais contundente, assim, o deslocamento das crianças fica mais complicado, alguns pais acompanham em parte do trajeto sendo que parte do caminho a criança percorre sozinha, outros vão de bicicleta e alguns poucos a cavalo. Alguns moradores dessas localidades ${ }^{3}$ assumem sua preocupação com a fragilidade do sistema educacional, que desconhece a história desse grupo e não contribui para a compreensão das crianças sobre sua realidade em sua dimensão ambiental, política e cultural, tanto no que diz respeito à capacidade de (re)invenção desse modo de vida, quanto ao acesso a uma educação de qualidade, em que suas especificidades, sua história, sua visão política, suas lutas, sua religiosidade, sua vivência espacial, entre outros, ganhem espaço e se consolidem em seu valor intrínseco.
3 Depoimentos de Domingos Kalunga e Otília Kalunga colhidos durante trabalho de campo realizado na comunidade de Vão de Almas do Território Kalunga por Maria Lidia Bueno Fernandes em 01/09/2015 e 03/09/2015, respectivamente.

Rev.latinoam.cienc.soc.niñez juv 16 (1): 213-226, 2018 http://revistalatinoamericanaumanizales.cinde.org.co doi:10.11600/1692715x.16112

\section{Metodologia}

Em termos metodológicos trata-se de uma pesquisa qualitativa, que, segundo (Chizzotti, 2003, p. 221) "implica em uma partilha densa com pessoas, fatos e locais que constituem objetos de pesquisa, para extrair desse convívio os significados visíveis e latentes que somente são perceptíveis a uma atenção sensível”. Envolveu diferentes momentos de trabalho, desde levantamento bibliográfico, contemplando a produção existente acerca da comunidade estudada, até visitas às escolas, às casas dos moradores, ancoradas na perspectiva da observação participante, que implica segundo (Valadares, 2007) em um processo longo, com uma fase exploratória bem demarcada, supõe uma profunda interação entre pesquisador/pesquisado e conta com um informante-chave, no nosso caso, o Sr. Domingos, que nos recebeu em sua casa e nos acompanhou nas primeiras visitas às casas dos outros moradores da comunidade. Ainda sobre a observação participante, a autora adverte que: "implica saber ouvir, escutar, ver, fazer uso de todos os sentidos”. É preciso aprender quando perguntar e quando não perguntar, assim como que perguntas fazer na hora certa (Valadares, 2007, p. 154).

Parte considerável da pesquisa deu-se pelo contato com as crianças a partir da estadia na residência do $\mathrm{Sr}$ Domingos e família, com visitas às escolas e a membros da comunidade, outrossim, houve participação em festas tradicionais, convivência cotidiana e atividades com as crianças da família que participaram mais ativamente desta pesquisa.

Os trabalhos de campo ocorreram em cinco oportunidades até o presente momento. 


\begin{tabular}{|c|c|c|}
\hline Data & Local de Estadia & Atividade desenvolvida \\
\hline $\begin{array}{c}01 / 09 / 2016 \text { a } \\
04 / 09 / 2016\end{array}$ & $\begin{array}{l}\text { Casa do Sr Domingos no Córrego da } \\
\text { Serra }\end{array}$ & $\begin{array}{l}\text { Visita às escolas: Córrego da Serra, Joana Pereira e Santo } \\
\text { Antônio, visita às casas dos moradores: Dona Luiza, Dona } \\
\text { Rosa, Sr. Manoel, entre outros. Acompanhamento das } \\
\text { atividades desenvolvidas pelas crianças nas escolas. }\end{array}$ \\
\hline $\begin{array}{l}09 / 10 / 2015 \text { a } \\
11 / 10 / 2015\end{array}$ & $\begin{array}{c}\text { Casa da Eva, professora do Colégio } \\
\text { Santo Antônio }\end{array}$ & $\begin{array}{l}\text { Visita à escola, passeio pelos arredores da escola, entrevista } \\
\text { com professores, visita à casa da Marisa, professora local. } \\
\text { Leitura de material produzido pelas crianças na escola }\end{array}$ \\
\hline $\begin{array}{l}6,7 \text { e } 8 \text { de } \\
\text { novembro }\end{array}$ & $\begin{array}{l}\text { Casa do Sr Domingos no Córrego da } \\
\text { Serra. }\end{array}$ & $\begin{array}{l}\text { Visita à casa da Dona Fiota, Sr. Valdemar e reconhecimento } \\
\text { do território. Conversa sobre as atividades cotidianas na } \\
\text { comunidade. }\end{array}$ \\
\hline $\begin{array}{l}9 \text { e } 10 \text { de } \\
\text { agosto de } \\
\quad 2016\end{array}$ & $\begin{array}{l}\text { Casa do Sr Domingos no Córrego da } \\
\text { Serra }\end{array}$ & $\begin{array}{l}\text { Trabalho com as crianças, pescaria, montagem de arapuca, } \\
\text { preparação para a festa de Nossa Senhora da Abadia, do } \\
\text { Espírito Santo e de Nossa Senhora das Neves }\end{array}$ \\
\hline $\begin{array}{l}13 \text { e } 14 \text { de } \\
\text { agosto de } \\
2016\end{array}$ & $\begin{array}{l}\text { Casa do Senhor Domingos na } \\
\text { Comunidade Capela. }\end{array}$ & $\begin{array}{l}\text { Participação das atividades preparatórias para a festa. } \\
\text { Decoração, procissão com incensos, visita ao festeiro, } \\
\text { Zezinho, que na festa assume a denominação de imperador. }\end{array}$ \\
\hline
\end{tabular}

Figura 1. Tabela elaborada a partir de dados de Trabalho de Campo na Comunidade Vão de Almas.

\section{Vivência, Reelaboração Criadora e Protagonismo na comunidade em questão}

Abordar as vivências infantis atreladas aos contextos culturais lança luz ao protagonismo da criança na produção do espaço. Essas crianças constroem suas linguagens espaciais a partir de sua vivência no território, do conhecimento sobre as festas, plantas, caminhos, grotões, morros e clima. Assim, a partir dos pressupostos teórico-metodológicos do campo da Geografia da Infância em diálogo com os aportes que a teoria histórico-cultural trouxe nos últimos anos, "reconhecemos que as crianças estão presentes nas paisagens, constroem/destroem suas formas, estabelecem lugares e territórios, vivem seus afetos, seus desejos, poderes, autorias e heteronomias, inventam-nos, arquitetam e des-arquitentam, o aceitam, o negam” (Grupegi, 2016).

Na perspectiva de construir elementos para dialogar com os conceitos (Vigotski, 2009, 2010) abordaremos os conceitos de vivência (perejivanie), que se refere à unidade fundada entre pessoa-meio e o de reelaboração criadora (tvortcheskaia pererabotka) que implica no potencial criativo/criador da pessoa para (re) interpretar a cultura, a partir de uma atividade organizadora interna. Ambos os conceitos contribuem para se compreender como se procede o enraizamento no mundo, na cultura, de forma que, seja possível a renovação da própria cultura. Abordamos ainda a forte vinculação entre território e cultura na configuração de identidades a partir de um universo simbólico, ancorado nos campos de sentido e significado que os seres humanos constroem na e pela relação com seu espaço e com o universo material que o circunda.

Para analisar o cotidiano da criança nesse contexto, cumpre destacar que, em contraponto a esta realidade inóspita do ponto de vista da presença do Estado e do acesso aos bens e serviços mínimos, temos uma comunidade vibrante e potente do ponto de vista humano e cultural, e é nesse cenário que pudemos observar uma infância cercada de cuidados dos adultos, ao mesmo tempo em que se mostra protagonista e autônoma, no que tange aos aspectos da vida cotidiana, (figura 1) dessa forma acreditamos que abordar as vivências infantis atreladas aos contextos culturais contribui para lançar luz sobre o protagonismo da criança na produção desse espaço, tendo em vista que elas constroem suas linguagens espaciais a partir de sua vivência no território, do conhecimento sobre as festas, 
plantas, caminhos, grotões, morros, do clima, do manejo dos instrumentos, do artesanato, da pesca, da quebra do coco (pindoba) para fazer o azeite ou a paçoca, entre outros.

Dito de outra maneira, a pesquisa sobre infância, elaborada de uma perspectiva adultocêntrica, olha e analisa o universo infantil como o local da falta, da negatividade, assim, trabalha sem a ancoragem no tempo e no espaço desta infância, portanto, deslocadas de seus espaços e de seus tempos. Nossa perspectiva, ao localizar essa infância e ancorá-la temporal e espacialmente, é compreender as crianças como agentes produtores do espaço que gestam e dão significados as suas espacialidades, construindo lugares, territórios e interferências nas paisagens. As crianças são assim, produtoras de culturas próprias, constituídas na interface do espaço geográfico e do tempo histórico (Grupegi, 2016, p. 1).

Cabe ainda destacar, que, concordando com (Qvortrup, 1983), em sua análise que considera as forças sociais, ou melhor, a variável estrutural e seus macroparâmetros como importantes elementos na pesquisa envolvendo o universo infantil, defendemos que as crianças tem um papel bastante ativo na sociedade em que estão inseridas, o autor menciona o fato de influenciarem e serem influenciadas, e de ocuparem posição na divisão social do trabalho, desenvolvendo, em principio, suas tarefas escolares, entretanto, no caso das crianças na comunidade do Vão de Almas, as crianças estão envolvidas com atividades complementares a de seus pais, e assim, ocupam posição na divisão social do trabalho, assumindo diversas tarefas e contribuindo principalmente nas atividades de subsistência e na elaboração de artefatos para as necessidades cotidianas. Nesse sentido, o autor destaca a "força radical" dessa participação.

todas as vezes que as crianças interagem e se comunicam com a natureza, com a sociedade e com outras pessoas, tanto adultos quanto pares, elas estão contribuindo para a formação quer da infância quer da sociedade (Qvortrup, 1983, p. 206).

Para o autor a infância é influenciada de modo particular pelas forças sociais. Nesse sentido, percebe-se pela ação/atividade que desenvolvem no seu cotidiano.

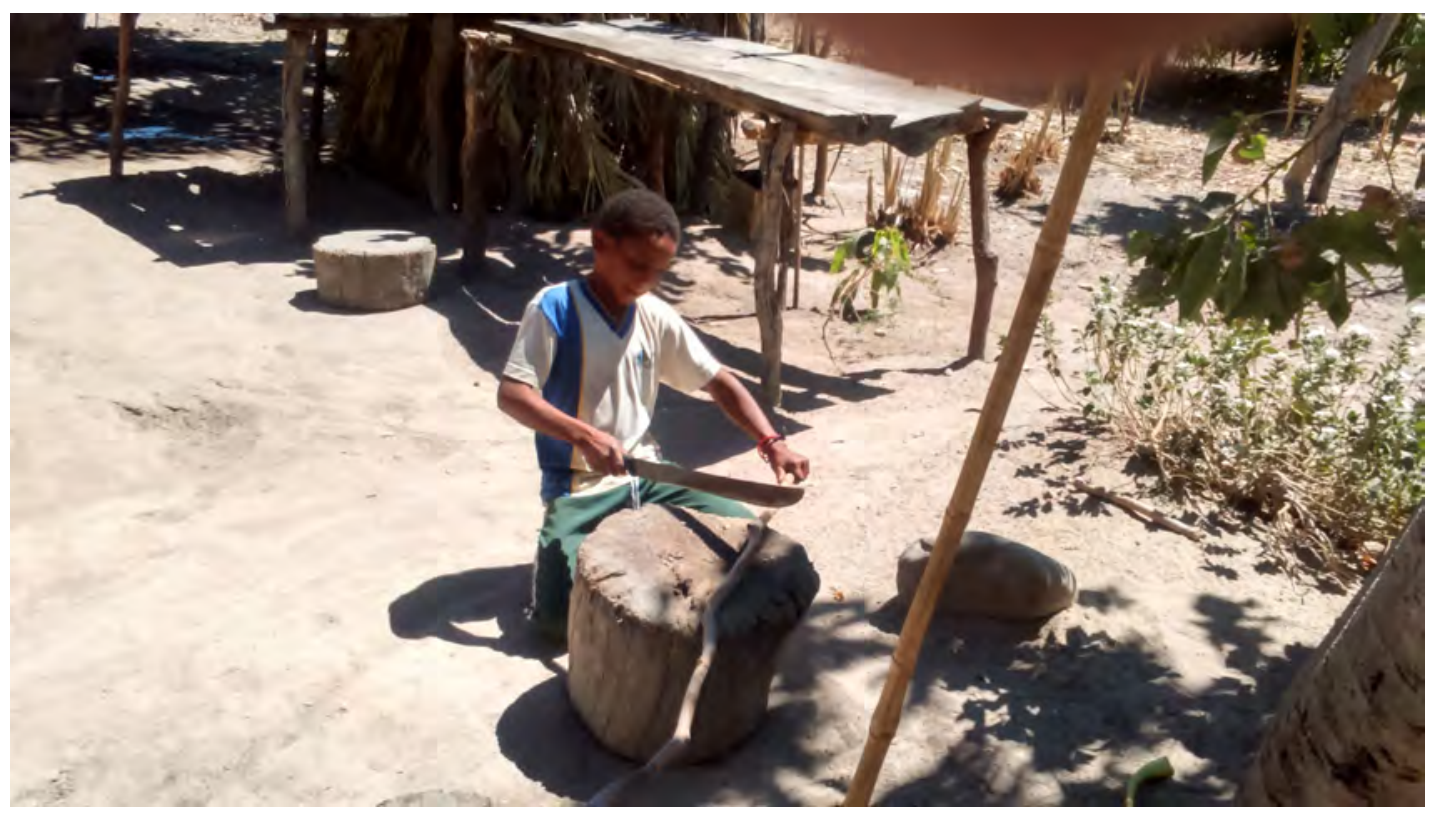

Figura 2. A habilidade para manejo dos instrumentos de uso cotidiano pode-se notar desde cedo. Aqui o foco é na preparação do pau que lhe permitirá montar a forquilha da arapuca recémconstruída. Foto: Reinaldo Diniz. Agosto de 2016. Residência do Sr. Domingos e Sra. Domingas (Bila), do Pablo, do Thiago e da Alessandra. Vão de Almas/GO. 


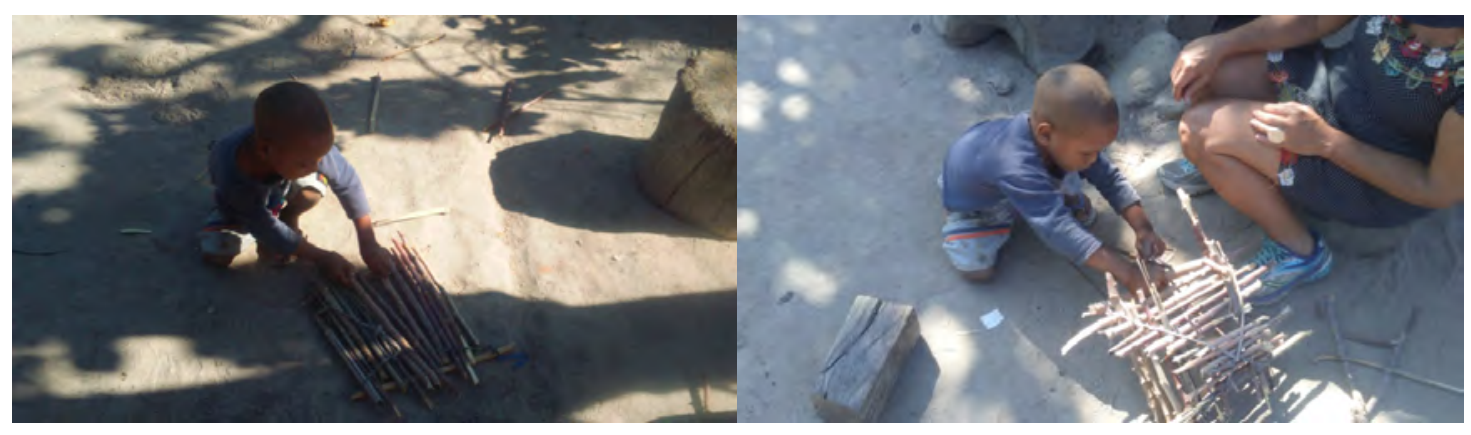

Figura 3. Observando o irmão, Tiago monta sua própria arapuca, recebe críticas, pois usa "paus" de diferentes qualidades, inclusive os da mandioca, que, nos dizeres de Pablo (o irmão mais velho) não prestam. Foto: Reinaldo Diniz. Agosto de 2016. Residência do Sr. Domingos e Sra. Domingas (Bila), do Pablo, do Thiago e da Alessandra. Vão de Almas/GO.

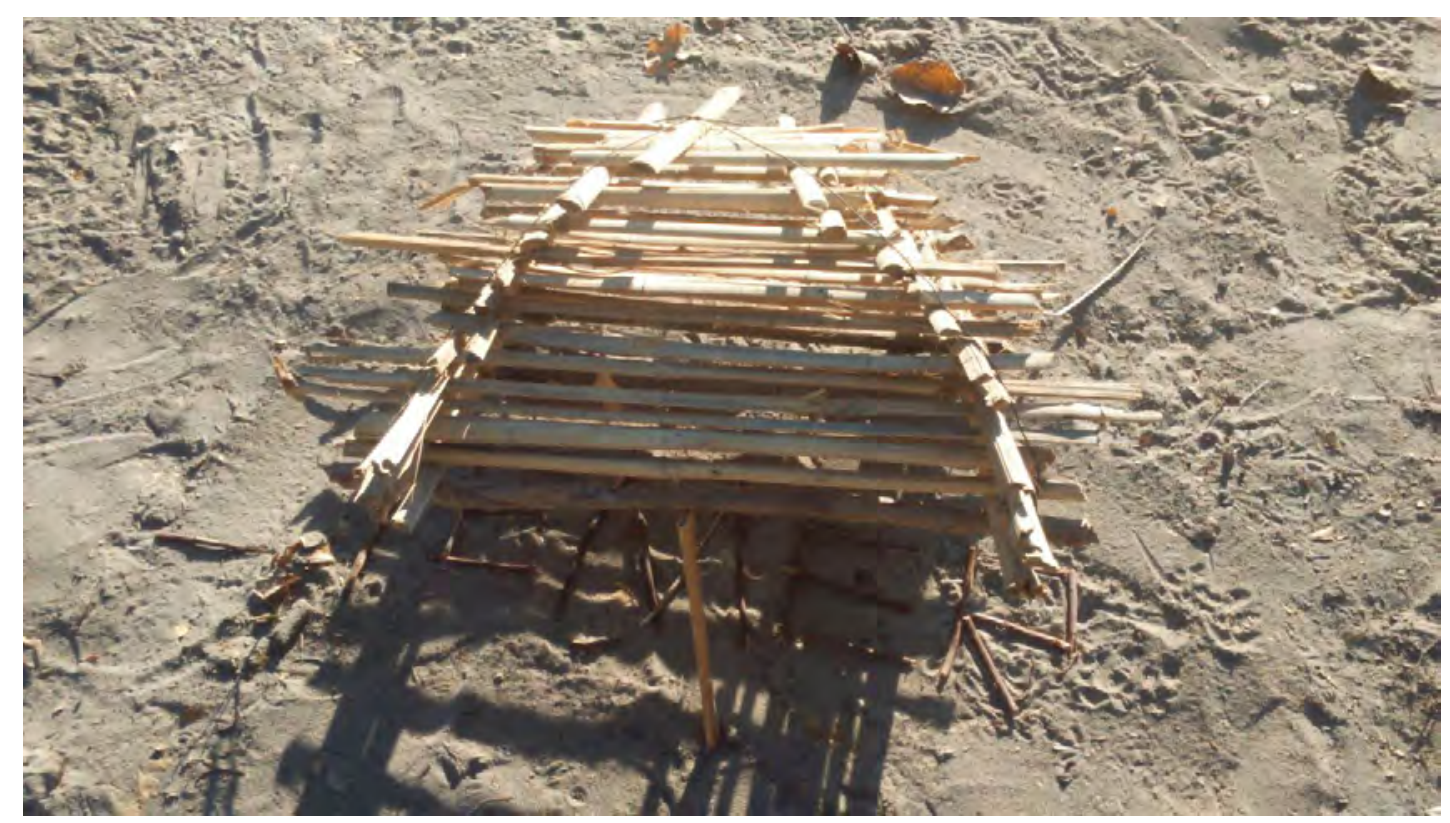

Figura 4. A gama de conhecimentos envolvidos na construção da arapuca, para pegar pequenos animais que comporão a dieta da família é impressionante. Assim, da seleção dos paus, da fibra que os entrelaçarão, à preparação da forquilha, que dá sustentação à arapuca, até a escolha do local para colocá-la e a própria montagem da armadilha, passa-se por uma série de passos, que requer conhecimentos diversos e sofisticados, que as crianças mais velhas passam às mais novas. Foto: Reinaldo Diniz. Agosto de 2016. Residência do Sr. Domingos e Sra. Domingas (Bila), do Pablo, do Thiago e da Alessandra. Vão de Almas/GO. 


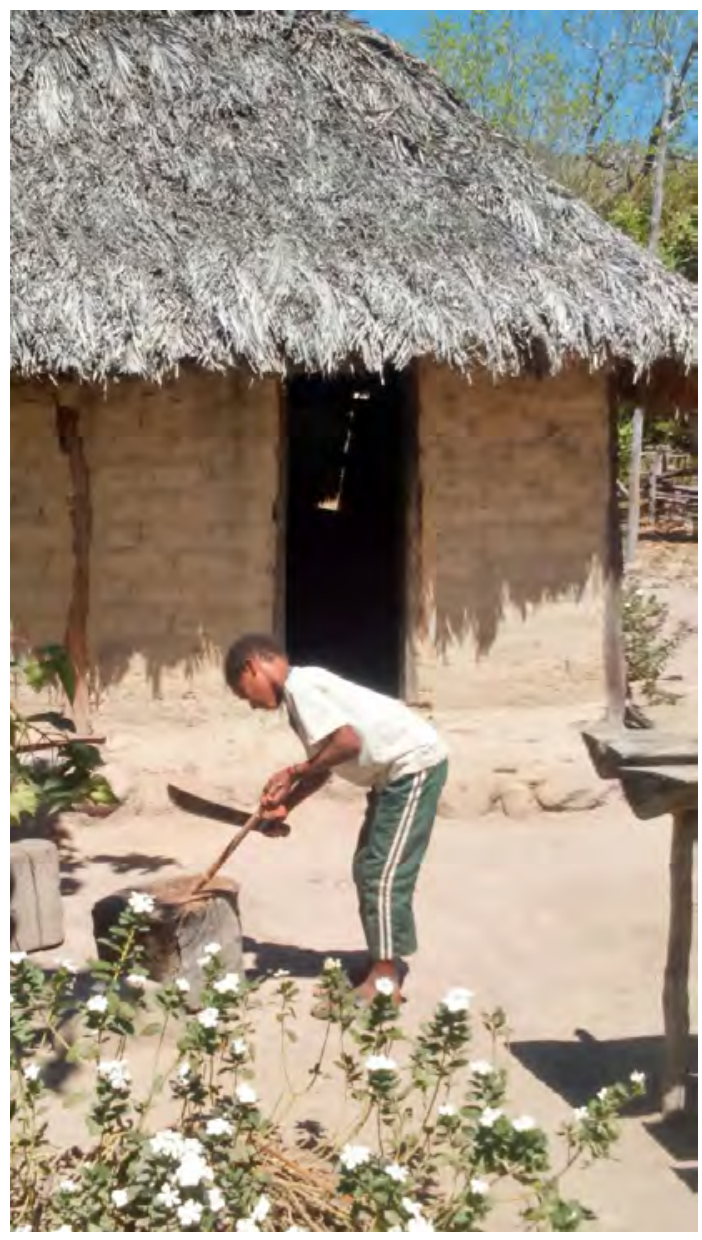

Figura 5. Nesta imagem é possível observar a casa de adobe, o telhado de palha, a estrutura de madeira, o entorno da casa, com flores, jiraus e tocos de madeira. Foto: Reinaldo Diniz. Agosto de 2016. Residência do Sr. Domingos e Sra. Domingas (Bila), do Pablo, do Thiago e da Alessandra. Vão de Almas/GO.

Chamou-nos a atenção a falta de brinquedos na casa de adobe, blocos de barro cru secados ao sol, recoberta de telhado de palha, o que, consideramos um convite para o desenvolvimento da imaginação na perspectiva do brincar, tão caro, nas abordagens de (Vigotski, 2009). Entretanto, o uso de um pedaço de papelão simulando um carro, o chutar um fruto denominado marmelo no lugar da bola, a construção das arapucas com pedaços de paus recolhidos no quintal, a pescaria, o banho de rio, de chuveiro (feito de garrafa pet e situado na área externa da casa, cercado de palha da pindoba), o tocar do tambor, instrumento bastante relevante nas festividades da comunidade, a observação dos astros, a condição de localização no espaço, bem como a responsabilidade em partilhar as tarefas do dia a dia, nos fizeram perceber as possibilidades concretas de ações compartilhadas, (re) inventadas nessa infância tão peculiar.

Assim, compartilhamos as considerações de Prestes, quando aborda o conceito de Vivência em Vigostki que, “desde o seu nascimento a criança está mergulhada na cultura, o meio social é constitutivo da pessoa” (Prestes, 2013, p. 303). Nesse sentido, Lopes (2016) e Prestes (2013) trazem a ideia de "enraizamento na cultura" como forma ativa de construir a unidade entre pessoa-meio. O conceito de Vivência nesta perspectiva assume o significado de "conhecimento adquirido no processo de viver 
ou vivenciar uma situação ou [no processo] de realizar alguma coisa” (Vigotski, 2010, p. 683, nota do tradutor). Assim, Vigotski afirma:

A vivência de uma situação qualquer, a vivência de um componente qualquer do meio determina qual influência essa situação ou esse meio exercerá na criança. Dessa forma, não é esse ou aquele elemento tomado independentemente da criança, mas, sim, o elemento interpretado pela vivência da criança que pode determinar sua influência no decorrer de seu desenvolvimento futuro (Vigotski, 2010, pp. 683-684).

Jerebtsov (2014), ao analisar o conceito de Vivência (Perejvania) na obra de Vigotski, apresenta-o como sendo a relação entre o que a criança possui como referência constitutiva de sua personalidade e a própria constituição de sua personalidade. Para o autor elas (as vivências) "refletem a unidade do 'interno' e do 'externo' e também a unidade afeto-intelecto" (Jerebtsov, 2014, p. 16). Assim, para o autor as "Vivências são o processo de formação pela personalidade da sua relação com as situações da vida, a existência em geral com base nas formas e valores simbólicos transformados pela atividade interna, emprestados da cultura e devolvidos a ela.” (Jerebtsov, 2014, p. 19). Nesse sentido afirma que

a zona de desenvolvimento iminente elabora as condições, os instrumentos, o espaço semântico para a vivência de um novo eu. Em atividade conjunta, na cooperação, na coexistência, em convivência, nasce o novo Eu. E esse novo $\mathrm{Eu}$ exige vivencias para a elaboração de determinações, adaptações para o Eu renovado.

Ou seja, quando analisamos o cotidiano da infância na comunidade, é possível perceber, nos ínfimos detalhes, a construção do enraizamento na cultura, a partir, inclusive da cooperação, da aprendizagem na e com a presença do outro: irmão, amigo, pai, mãe, parentes, vizinhos, entre outros. Nesse sentido, se, defendemos que as crianças são protagonistas, capazes de reelaborarem a própria cultura, estabelecem-se, então, as bases para a compreensão do conceito de Reelaboração Criadora (Tvortcheskaia Pererabotka).

No homem, a plasticidade se evidencia particularmente na disposição orgânica característica da espécie para a incorporação da cultura e da possibilidade de conservação e (trans)formação da experiência, que reúne as marcas do vivido e a abertura para o possível (Smolka \& Vigotski, 2009, p. 12).

Vigotski (2009, p. 14) refere-se a essa atividade criadora como desdobramento da atividade reprodutiva e a apresenta como possibilidade concreta à criação de algo novo, de ações novas a partir, não mais da reprodução, mas da combinação e da criação. Para o autor, a imaginação está na base de toda a atividade criadora e afirma que os objetos que nos cercam foram "feitos pelas mãos do homem”. Assim, terminamos este artigo apontando para o potencial transformador, criativo e criador, dessa infância, exposta a esse sistema de relações, na perspectiva de reinterpretação de sua própria cultura. 


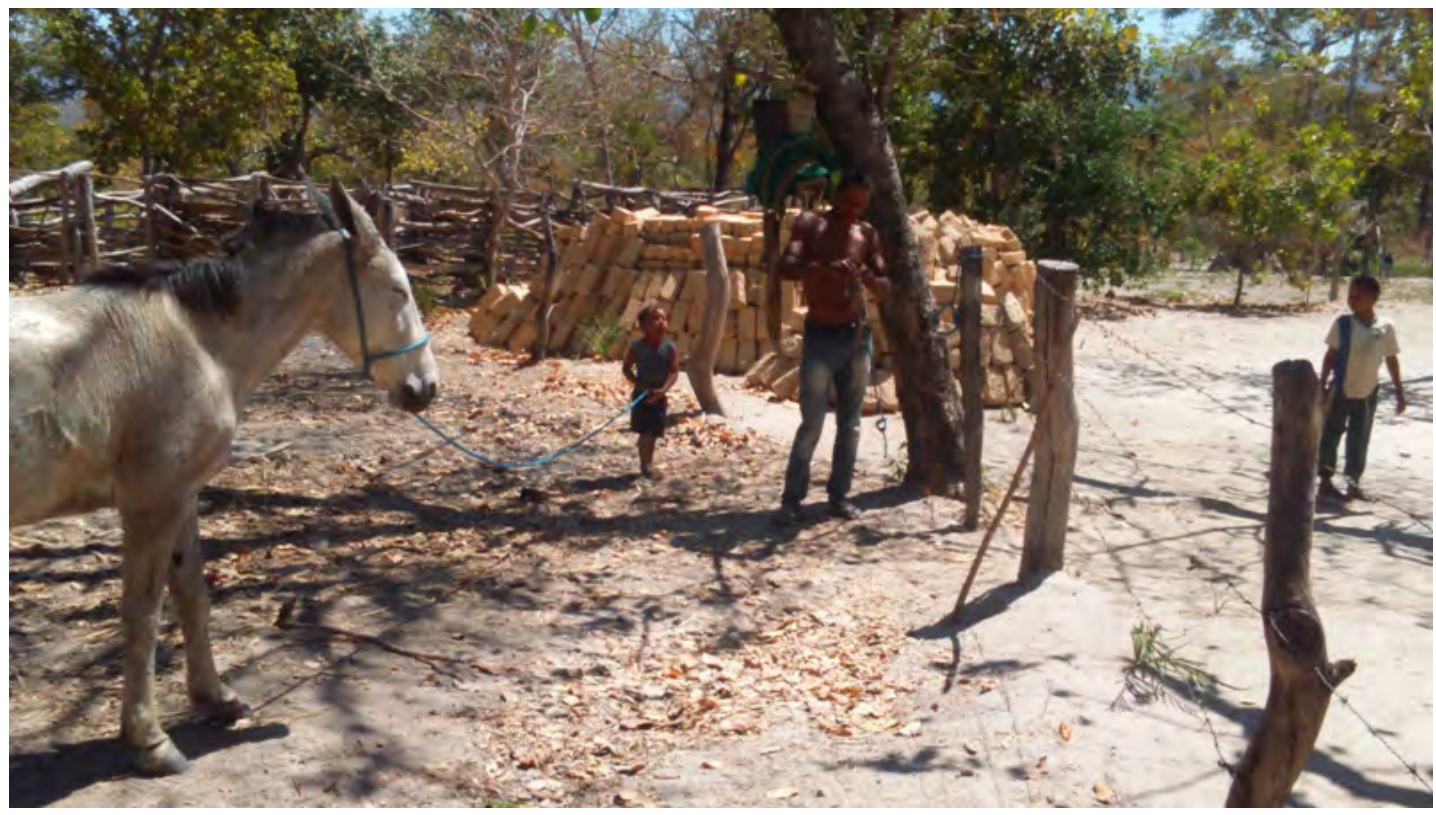

Figura 6. Ao fundo, os adobes feitos pela mãe e as crianças enquanto o pai trabalhava na cidade. Foto: Reinaldo Diniz. Agosto de 2016. Residência do Sr. Domingos e Sra. Domingas (Bila), do Pablo, do Thiago e da Alessandra. Vão de Almas/GO.

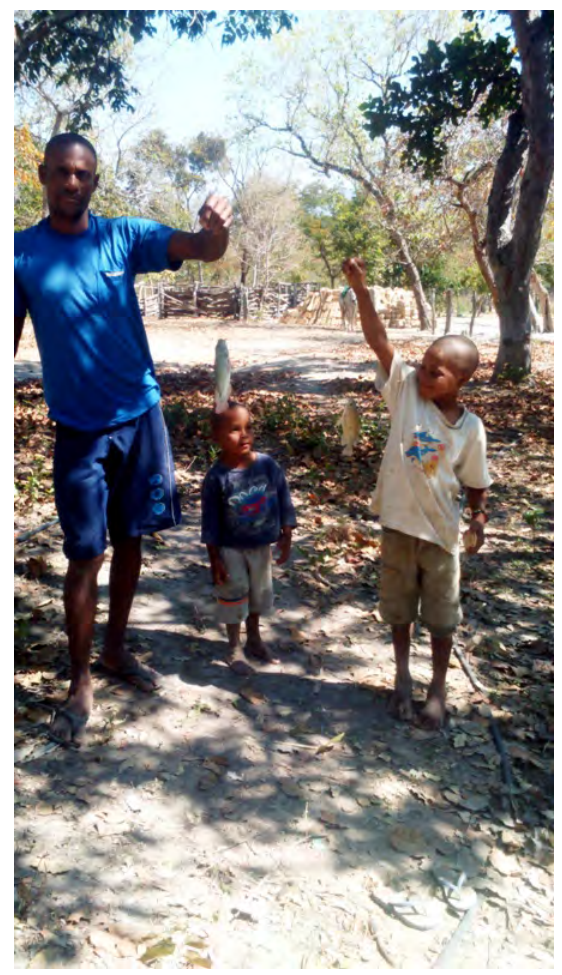

Figura 7. A pescaria em família, que traz o alimento para casa. A responsabilidade em partilhar as tarefas do dia a dia, enfim, são coisas que marcam profundamente essa infância. Foto: Reinaldo Diniz. Agosto de 2016. Residência do Sr. Domingos e Sra. Domingas (Bila), do Pablo, do Thiago e da Alessandra. Vão de Almas/GO. 


\section{Referências}

Almeida, M. de (1996). Em busca do poético do sertão. Espaço e Cultura, 6, 37-48.

Almeida, M. de (2010). Territórios de quilombolas pelos vãos e serras dos Laungas de Goiás-patrimônio e biodiversidade de sujeitos do cerrado. Ateliê Geográfico, 4(1), 36-63. doi:10.5216/ag.v4i9.9389

Avelar, G. A., \& Paula, M. V. de. (2009). Comunidade Kalunga: trabalho e cultura em terra de negro. GEOgraphia, 5(9), 115131.

Baiocchi, M. de N. (1990). Relatório técnico científico para demarcação do sítio histórico. Goiânia: UFG.

Bandeira, M., Dantas, T., \& Mendes, E. (1990). Projeto de mapeamento e sistematização das áreas de comuniaddes remanescentes de quilombo mata cavalo (MT). Cuiabá: Universidade de Cuiabá.

Bertrand, P. (2011). História da terra e do homem no Planalto Central: eco história do Distrito Federal-do indígena ao colonizador. Brasília: Universidade de Brasília.

Certeau, M. de (1982). A escrita da história. Rio de Janeiro: Forense.

Chizzotti, A. (2003). A pesquisa qualitativa em ciências humanas e sociais: evolução e desafios. Revista Portuguesa de Educação, 16(2), 221-236.

Grupegi, B. (2016). Resumo para apresentação de trabalho do grupo de pesquisa no Grupeci Memeo. Recuperado de: http:// geografiadainfancia.blogspot.com.br

Jerebtsov, S. G. (2014). A cidade de L. S. In Veresk (Ed.), Estudos sobre a perspectiva histórico-cultural de Vigostski (pp. 7-29). Brasília: Uniceub.

Karasch, M. (1996). Os quilombos do ouro na capitania de Goiás. In F. dos S. Reis, \& J. J. Gomes (Eds.), Liberdade por um fio: história dos quilombos no Brasil (pp. 240263). São Paulo: Companhia das Letras.

Lifschtz, J. A., \& Silva, J. B. (2007). Modernidades retroativas na América Latina. Caxambu: Anpocs.

Lopes, J. J. M. (2016). Depoimento em aula da disciplina e pesquisa com vbebês $e$ crianças. Niteroi: Universidade Federal Fluminense.

Massey, D. B. (2015). Pelo espaço: uma nova política da especialidade. Rio de Janeiro: Bertrand Brasil.

Palacin, L. (1972). Goiás 1722-1822: estrutura e conjuntura numa capitania de minas. Goiânia: Oriente.

Prestes, Z. (2013). A sociologia da infânica e a teoria histórico-cultural: algumas considerações. Revista de Educação Pública, 22(1), 295-304.

Qvortrup, J. (1983). Nove teses sobre a infânica como fenômeno social. Pro-Posições, 22(1), 199-211.

Secretaria de Educação Fundamental. (2001). Uma história do povo Kalunga. Brasília: SEF.

Smolka, A. L., \& Vigotski, L. S. (2009). Imaginação e criação na infânica. São Paulo: Ática.

Strahler, A. H., \& Strahler, A. (2005). Physical geography: Science and systems of the human environment. New York: Wiley.

Valadares, L. (2007). Os dez mandamentos da observação participante. Revista Brasileira de Ciências Sociais, 22(63), 153-155.

Vázquez, F. (2001). La memória como accion social relaciones, significados $y$ imaginário. Barcelona: Paidós.

Vigotski, L. S. (2009). Imaginação e criação na infância. São Paulo: Ática.

Vigotski, L. S. (2010). Quarta aula: a questão do meio na pedagogia. Psicologia USP, 21(4), 681-701. 